\title{
Indentation induced local polarization reversal in La doped $\mathrm{BiFeO}_{3}$ ceramics
}

\author{
A. S. Abramov, D. O. Alikin, V. V. Yuzhakov, A. V. Nikitin, S. I. Latushko, D. \\ V. Karpinsky, V. Ya. Shur, and A. L. Kholkin
}

\section{QUERY SHEET}

This page lists questions we have about your paper. The numbers displayed at left can be found in the text of the paper for reference. In addition, please review your paper as a whole for correctness.

Q1. Figure 6 was not cited in the text so a citation has been inserted. Please provide a correction if this is inaccurate.

Q2. References [17 and 29] are duplicate references. Hence duplicate reference has been deleted and renumbered, kindly check and confirm.

\section{TABLE OF CONTENTS LISTING}

The table of contents for the journal will list your paper exactly as it appears below:

Indentation induced local polarization reversal in $\mathrm{La}$ doped $\mathrm{BiFeO}_{3}$ ceramics A. S. Abramov, D. O. Alikin, V. V. Yuzhakov, A. V. Nikitin, S. I. Latushko, D. V. Karpinsky, V. Ya. Shur, and A. L. Kholkin 


\title{
Indentation induced local polarization reversal in La doped $\mathrm{BiFeO}_{3}$ ceramics
}

\author{
A. S. Abramov ${ }^{\text {a }}$, D. O. Alikin ${ }^{\text {a,b }}$, V. V. Yuzhakov ${ }^{\text {a }}$, A. V. Nikitin ${ }^{c}$, S. I. Latushko ${ }^{c}$, D. V. \\ Karpinskyc, V. Ya. Shur ${ }^{a}$, and A. L. Kholkin ${ }^{a, b}$

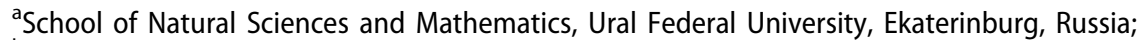 \\ ${ }^{b}$ Department of Physics \& CICECO - Aveiro Institute of Materials, University of Aveiro, Aveiro, Portugal; \\ 'Scientific-Practical Materials Research Centre of NAS of Belarus, Minsk, Belarus
}

\begin{abstract}
Stress-induced local polarization reversal was studied in La doped $\mathrm{BiFeO}_{3}$ ceramics under the action of Berkovich-type prism indentation. Piezoresponse force microscopy was used for detailed study of domain structure before and after local polarization reversal. Two mechanisms of domain formation under the action of the mechanical loading were revealed: (1) direct stress-induced and (2) stress mediated by grain clamping. Critical stress value for local polarization reversal was extracted from the dependence of the switched area on the applied loading force.
\end{abstract}

\section{ARTICLE HISTORY}

Received 29 August 2018

Accepted 26 November 2018

\section{KEYWORDS}

bismuth ferrite; mechanical

loading; indentation;

polarization reversal;

domain structure

\section{Introduction}

Ferroelectric materials are widely used for variety of electromechanical applications such as transducers and actuators [1,2], where they are protractedly exposed by electrical and mechanical loads. While polarization reversal under the action of electric field has been comprehensively studied for decades, influence of mechanical stress on it is still not totally understood. Mechanical stress was shown to induce phase transitions [3-5], modification of electromechanical properties $[6,7]$, and polarization reversal $[8,9]$ in ferroelectric materials. By analogy with electric field induced local polarization reversal, where non-uniform electric field is created by the biased tip of scanning probe microscope (SPM), indentation of a ferroelectric with enough load can induce polarization reversal [10-12]. This method looks attractive to go deeper in understanding of domain wall motion under the action of mechanical loading. Indentation induced polarization reversal was studied in the past in relaxor PMN-PT [10], $\mathrm{BaTiO}_{3}$ [13], tetragonal $\mathrm{ZrO}_{2}$ [11] and $\mathrm{SrTiO}_{3}$ [14] single crystals, as well as PZT [15] and $\mathrm{ZrO}_{2}$ [5] piezoelectric ceramics, where it was generally attributed to the direct influence of stress and strains induced by the mechanical loading. Nevertheless, it must be noted that the particular focus of the previous works was on single crystals as more simple systems $[13,16,17]$. In ferroelectric ceramics, specific conditions of domain growth exist, for example, domain wall mobility can be limited by orientation of neighboring grains [18]. Grain boundaries usually concentrate defects and can act both as pinning center for domain 
walls and as nucleation sites [19, 20]. In addition, specific conditions for the stress propagation exist in ceramics that, for example, hinder the movement of a crack (socalled, "crack grown resistance") [15]. The stress could have indirect effect on domain structure because of grain clamping that can mediate transfer strain from one grain to another.

In this work, we studied indentation induced local polarization reversal in La doped $\mathrm{BiFeO}_{3}$ (BLFO) ceramics. $\mathrm{BiFeO}_{3}$ (BFO) ceramics are perspective lead-free material for electro-mechanical applications [21], while doping by rare earth elements stabilizes the perovskite phase that decreases amount of secondary phases and, correspondently, leakage current $[22,23]$. Moreover, morphotropic phase boundary is realized in some doping concentration range that improves piezoelectric properties through the anti-polarto-polar phase transition [24-26]. Here, we showed that indentation of BLFO ceramics led to the visible domain structure transformation both under immediate place of indentation and in some area around. Details of the local polarization reversal by indentation were analyzed and switching mechanisms were discussed. Piezoresponse force microscopy (PFM) was shown to be useful technique for study of the switching under the action of mechanical load.

\section{Experimental}

The investigated samples of BLFO ceramics with molar La concentration 5\% were produced using the two-stage solid phase synthesis [27]. The initial high purity oxides were taken in the stoichiometric ratio and thoroughly mixed for about $30 \mathrm{~min}$ in a planetary mill RETSCH PM-100 using high purity isopropyl alcohol as a medium. Preliminary synthesis was made at $800^{\circ} \mathrm{C}$ for $2 \mathrm{~h}$, the final synthesis was performed at $900^{\circ} \mathrm{C}$ for $12 \mathrm{~h}$. The samples were quenched from the synthesis temperature down to room temperature. X ray diffraction (XRD) measurements were made on Rigaku D/MAX B dif fractometer using $\mathrm{Cu} K \alpha$ radiation. The XRD data were processed by the Rietveld method using the Fullprof software.

Since obtained BLFO ceramics were porous, one BFLO sample was permeated by epoxy under vacuum to decrease porosity and to facilitate the realization of the experiments. Further, both as-sintered and permeated by epoxy samples were rigorously polished by the diamond paste with abrasive size decreasing from 6 to $0.25 \mu \mathrm{m}$. Fine polishing was performed with colloidal silica (SF1 Polishing Suspension, Logitech, UK). Indentation of investigated samples was realized on scanning nano-hardness tester "NanoScan-4D" (FSBI «TISNCM», Russia) by application of local mechanical loading with diamond indenter of Berkovich type, trihedral pyramid, with $65.3^{\circ}$ angle between the axis of the pyramid and face, and $70.32^{\circ}$ equivalent angle of the cone. The curvature radius of the indenter was less than $100 \mathrm{~nm}$.

Domain structure before and after indentation was studied by vector piezoresponse force microscopy (VPFM) realized in scanning probe microscope Asylum MFP-3D (Asylum Research, Oxford Instruments, UK). MikroMasch NSC18/Pt probes with $30 \mathrm{~nm}$ tip radius, $75 \mathrm{kHz}$ free resonance frequency and $2.8 \mathrm{~N} / \mathrm{m}$ spring constant were used. Measurements were done with $20 \mathrm{kHz} 5 \mathrm{~V}_{\mathrm{AC}}$ voltage applied to the tip. R.cos $\Theta$ 
PFM signal was corrected by phase angle rotation in such a way that minimizes R.sin $\Theta$ signal and further plotted as image. We further address these images as piezoresponse.

\section{Results and discussion}

The grain size in BLFO ceramics was about 6-8 $\mu \mathrm{m}$. VPFM images of BLFO demonstrated mostly piezoelectrically active rhombohedral $(R 3 c)$ phase [28]. Domain structure consisted of prolong lamellar domains converging to one side with non-180-degree domain walls and irregular shaped watermark areas with 180-degree domain walls (Fig. 1). Piezoresponse distribution had discrete values of the measured signal (contrasts) corresponding to the different types of domains allowed by rhombohedral symmetry conditions. Non-180-degree domain walls are clearer seen in the in-plane phase signal, while out-of-plane signal was mostly corresponded to boundaries of watermark areas.

In order to study polarization reversal under the action of mechanical load, we made the indentation within matrix of points with linear growth of applied force from 10 to $50 \mathrm{mN}$. The scheme of indentation experiments is presented in Fig. 2a. During indentation, the loading curves $F=f(H=$ Fig. $2 \mathrm{~b})$ were built. These curves are real experimental analog of stress-strain curve $\sigma=[\underline{E}$, $t$ - onsists of three sections: (1) loading, when polarization switching occurs, (2) ceray - nolding at the constant load, and (3) uploading, when elastic relaxation of the loaded state occurs. At the uploading stage, backswitching of stress-induced domains can happen [12]. It is speculated that backswitching can give an impact to pop-up event at the finish of uploading [17]. As a result of indentation, Young modulus and hardness of BLFO ceramics were obtained: $80 \pm 10 \mathrm{GPa}$ and $2.5 \pm 0.2 \mathrm{GPa}$, correspondently.

Local polarization reversal under the action of indentation results in two principal changes of the domain structure: (1) immediate change in the area of plastic deformation and (2) change in the vicinity of the area of plastic deformation. Example of typical indentation and corresponding domain structure change inside the indentation area is presented in Fig. 3. Local polarization reversal led to appearance of a dense net of nanoscale domains in the area of plastic deformation (Fig. 2a, red area). For maximal loading in the corners of the prism, both out-of-plane and in-plane PFM revealed piezoresponse reduction caused by pressure-induced phase transformation to orthorhombic phase [29].

The other part of switching happened out of the area of plastic deformation. Three possible sources of the switching can be considered: (1) strain created by indentation, (2) indirect strain caused by grain clamping by the neighboring grains, and (3) electric field created by charge induced by piezoelectric effect as a result of indentation at the enclosing of plastic deformation area [30]. It was noticed that impact of the charge induced by piezoelectric effect was negligible in our experiment, because we observed mostly the motion of non-180-degree domain walls and shrinkage of in-plane domains (Fig. 4), while electric field was usually onated by the irregular shape domains with 180-degree walls [31]. Both other two p.-...omena were observed in our experiments. Areas with domain switched under the direct stress action were located in the proximity of the indent or indentation induced crack (Fig. 4, blue and green arrows). These domains spread in direction from the region of plastic deformation. It must be noted 
139

140

141

142

143

144

145

146

147

148

149

150

151

152

153

154

155

156

157

158

159

160

161

162

163

164

165

166

167

168

169

170

171

172

173

174

175

176

177

178

179

180

181

182

183

184
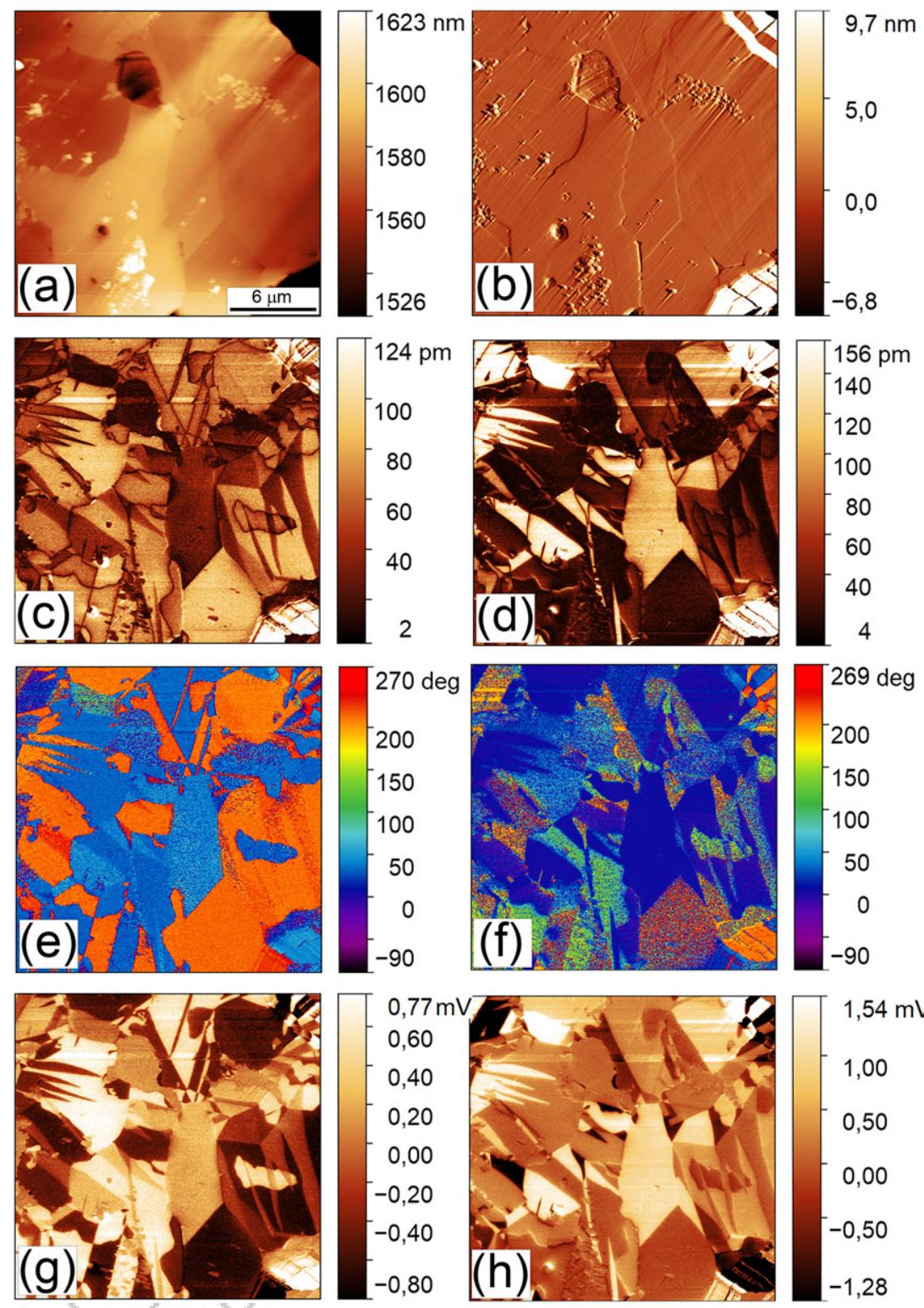

Figure 1. PFM images of the initial domain structure in BLFO ceramics: (a) topography; (b) deflection; amplitude: (c) out-of-plane and (d) in-plane; phase: (e) out-of-plane and (f) in-plane; piezoresponse: (g) out-of-plane and (h) in-plane.

that usually new domains were formed inside the initial domain structure. Growth of previously formed domain structure was observed rarely for polarization reversal by direct stress. Even domains with one direction of polarization often did not completely merge and residual domains remained (Fig. 4, blue and green arrows). The polarization reversal under the indirect stress by neighboring grains was responsible for shrinking initial ferroelastic domains (Fig. 4, red arrow).

Noticeable change of the domain structure was obtained at loads above $10 \mathrm{mN}$, str $)$ ng destruction of ceramics began for loads above $30 \mathrm{mN}$. Linear increase in the indentation 
185

186

187

188

189

190

191

192

193

194

195

196

197

198

199

200

201

202

203

204

205

206

207

208

209

210

211

212

213

214

215

216

217

218

219

220

221

222

223

224

225

226

227

228

229

230
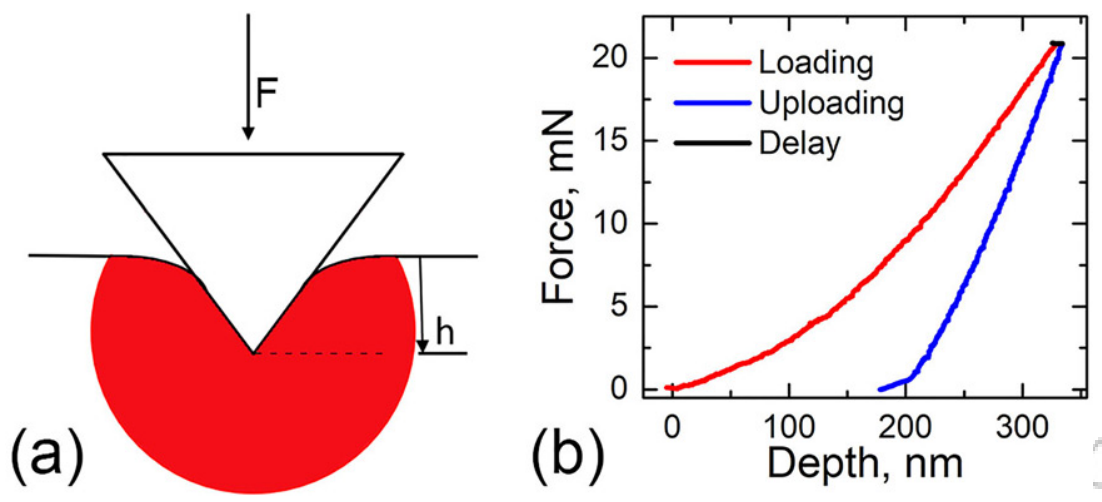

Figure 2. (a) Scheme of indentation by Berkovich type indenter. F - load force, $\mathrm{h}$ - penetration depth of indenter. Red semi-circle corresponds to the region with plastic deformation. (b) Typical loading curve for BLFO with $20 \mathrm{mN}$ loading force.
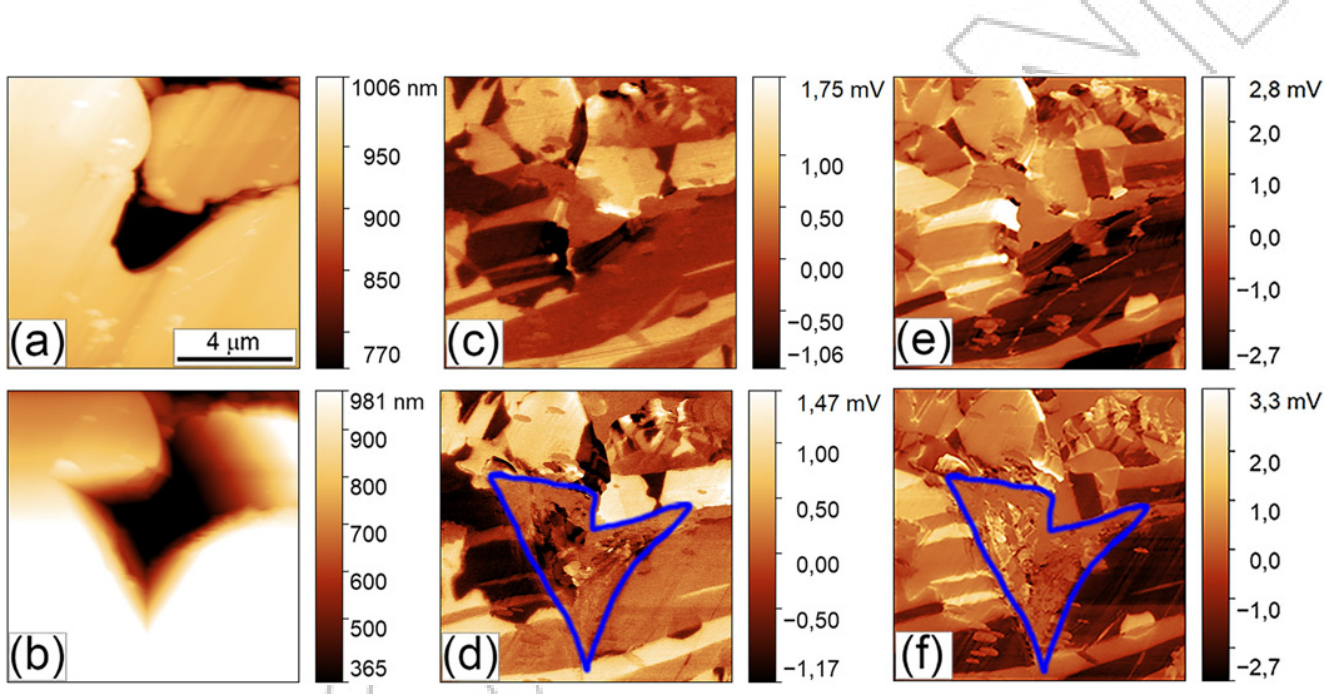

Figure 3. PFM images of the domain structure change in the indentation area. Topography: (a) before indentation and (b) after indentation; piezoresponse: out-of-plane (c) before indentation and (d) after indentation; in-plane (e) before indentation and ( $\mathrm{f}$ ) after indentation.

force from 10 up to $30 \mathrm{mN}$ led to linear increase in switching area (Fig. 5, red line). Critical value of stress can be found by the analysis of the switching area dependence on the load force (Fig. 5). From linear fitting, critical force necessary for polarization reversal was found $\mathrm{F}_{\mathrm{c}}=1.9 \mathrm{mN}$. This load force corresponded to penetration of the indenter about $75 \mathrm{~nm}$ into the ceramics surface and $0.13 \mu \mathrm{m}^{2}$ indentation area. Thus, critical stress $\sigma_{\mathrm{c}}=14.6 \mathrm{MPa}$ can be evaluated. This value is close to those obtained for single crystals and calculated from the first principals [6]. It must be noted that partial backswitching can happen after indenter uploading and thereby critical stress can be slightly different from one extracted from the fitting [12].

BLFO embedded in epoxy glue behave significantly different as compared with initial BLFO (Fig. 5). Local polarization reversal by indentation can be realized only by $30 \mathrm{mN}$, but mor $\Longrightarrow$ ress could be applied without comple rain destroying, up to $50 \mathrm{mN}$. 
231

232

233

234

235

236

237

238

239

240

241

242

243

244

245

246

247

248

249

250

251

252

253

254

255

256

257

258

259

260

261

262

263

264

265

266

267

268

269

270

271

272

273

274

275

276

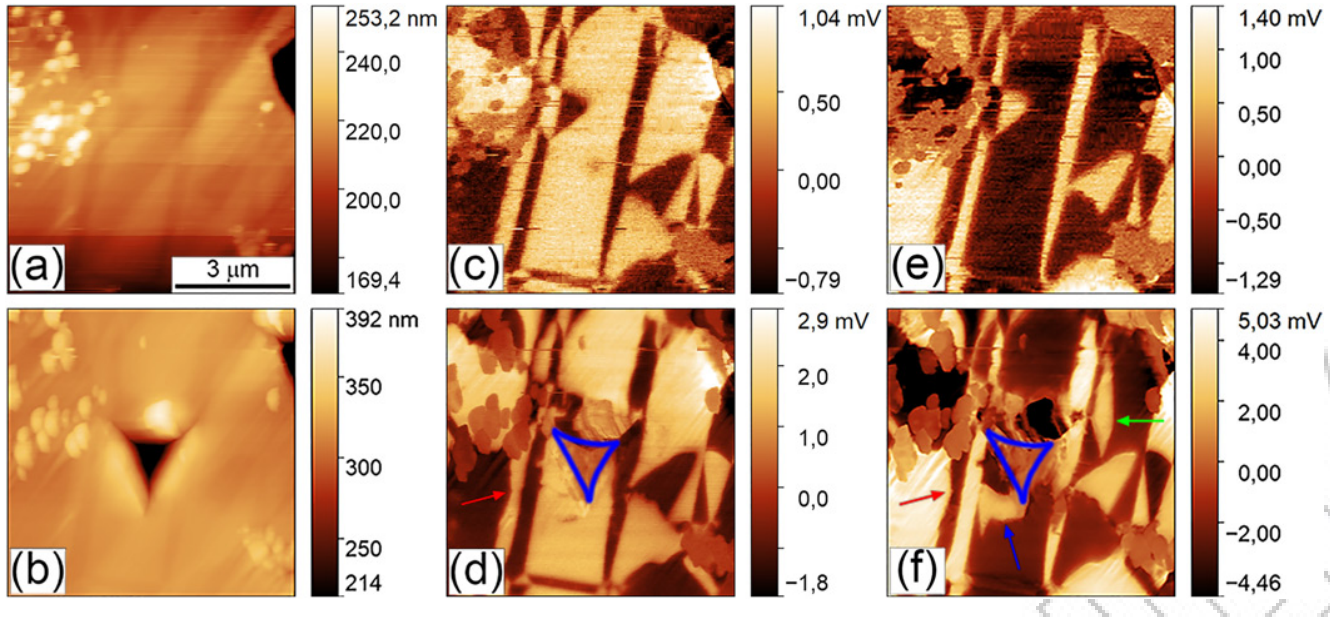

Figure 4. PFM images of the domain structure change in the vicinity of the indentation area. Topography: (a) before indentation and (b) after indentation; piezoresponse: out-of-plane (c) before indentation and (d) after indentation; in-plane (e) before indentation and (f) after indentation.

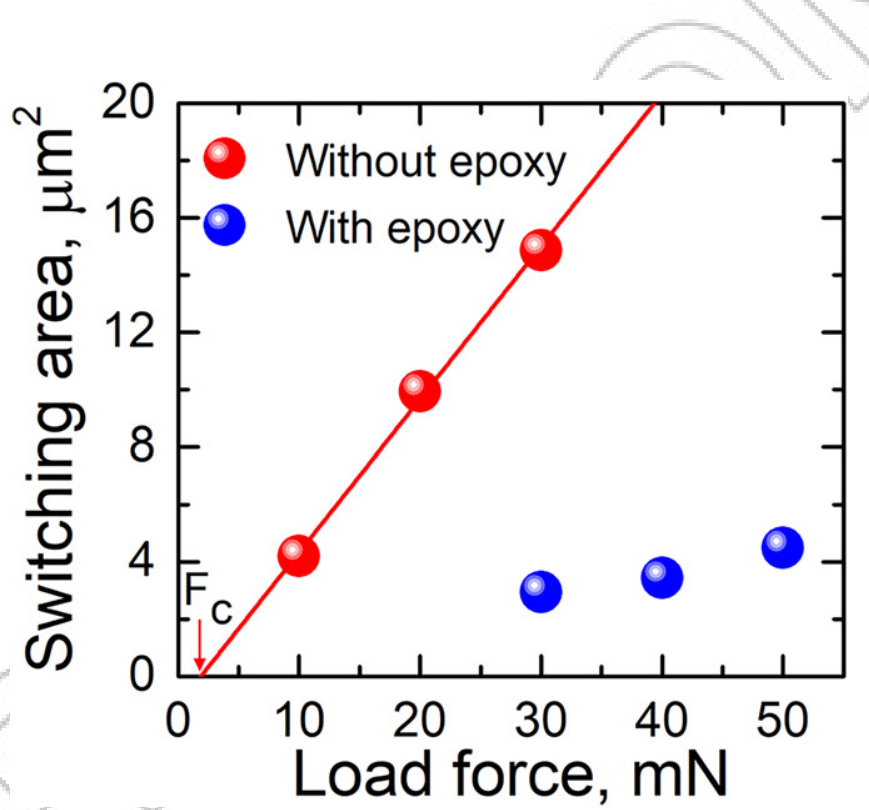

Figure 5. Dependence of the switching area on the load force for the initial BLFO ceramics (red color) and BLFO ceramics embedded in epoxy glue (blue line). Dots are responsible for the experimental data, while lines are fitting by linear function.

Domain structure after indentation was significantly less modified under the action of mechanical load (Fig. 5). Th act can be attributed to grain clamping, that is produced due to compression of epoxy and mediates stress to the grains of the ceramics. Stressinduced domains must change their size due to the piezoelectric effect and consequently overcome stress created by the grain clamping.

Significant increase in the force necessary for local polarization reversal can be attributed to backswitching under the action of compressive strain of epoxy binder. That is 

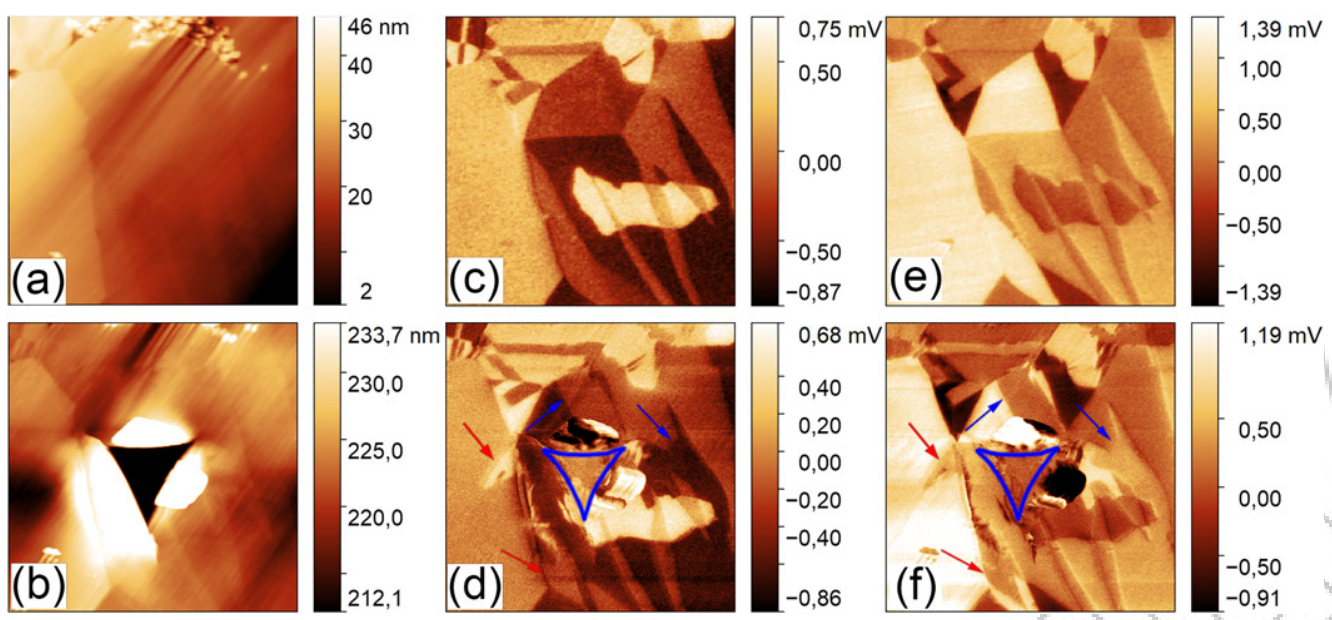

Figure 6. PFM images of the domain structure change in BLFO ceramics permeated by the epoxy. Topography: (a) before indentation and (b) after indentation; piezoresponse: out-of-plane (c) before indentation and (d) after indentation; in-plane (e) before indentation and ( $f$ ) after indentation.

why real critical force is hard to be evaluated in that case. Both switching mechanisms were observed in epoxy embedded ceramics as well: switching by direct stress (Fig. 5, blue arrows) and switching by indirect stress from neighboring grain (Fig. 5, red arrows). Due to the fact that polarization reversal was realized immediately near the grain boundary, nucleation of the new domains at the grain boundary under the action of clamping stress was observed (Fig. 5, red arrows).

\section{Conclusion}

Local polarization reversal under the action of mechanical load realized by Berkovich type prism indentation was studied in BLFO ceramics. Nanoscale domain structure and polar-to-nonpolar phase transition was observed in the area of plastic deformation. In the vicinity of the area of plastic deformation stress-induced ferroelastic domains appeared driving by conditions of mechanical energy minimization. Indirect action of grain clamping by neighboring grain resulted in shrinkage of existed ferroelastic domains and nucleation of new domains in the area of grain boundaries. Area of switching was found dependent linearly on the applied load force. The value of the critical stress $\sigma_{\mathrm{c}}=14.6 \mathrm{MPa}$ for indentation induced local polarization reversal was evaluated from fitting. Obtained experimental results are significant for understanding mechanical stress mediated depolarization effects in ferroelectric ceramics (Fig. 6).

\section{Acknowledgements}

The equipment of the Ural Center for Shared Use "Modern nanotechnology" Ural Federal University was used. The study was funded by RFBR (grant No. 17-52-04074) and BRFFR (grant No. F17RM-036), by Government of the Russian Federation (Act 211, Agreement 02.A03.21.0006). This work was developed within the scope of the project CICECO-Aveiro Institute of Materials, POCI-01-0145-FEDER-007679 (FCT Ref. UID/CTM/50011/2013), financed by national funds through the FCT/MEC and when appropriate co-financed by FEDER under 
the PT2020 Partnership Agreement. This project has received funding from the European Union's Horizon 2020 research and innovation program under the Marie Skłodowska-Curie grant agreement No 778070 .

\section{References}

[1] G. H. Haertling, Ferroelectric ceramics: history and technology. J. Am. Ceram. Soc. 82(4), 797 (1999). DOI: 10.1111/j.1151-2916.1999.tb01840.x.

[2] T. R. Shrout, and S. J. Zhang, Lead-free piezoelectric ceramics: alternatives for PZT. J. Electroceram. 19, 111 (2007).

[3] A. Y. Emelyanov, N. A. Pertsev, and A. L. Kholkin, Effect of external stress on ferroelectricity in epitaxial thin films. Phys. Rev. B. 66, 214108 (2002).

[4] G. Bai, and W. Ma, Phenomenological analysis of phase transitions in epitaxial perovskite ferroelectric thin films. Phys. Rev. B. 405, 1901 (2010). DOI: 10.1016/j.physb.2010.01.070.

[5] E. Liu et al., Strain-induced phase transformation behavior of stabilized zirconia ceramics studied via nanoindentation. J. Mech. Behav. Biomed. Mater. 75, 14 (2017). DOI: 10.1016/ j.jmbbm.2017.07.006.

[6] C. S. Lynch, The effect of uniaxial stress on the electro-mechanical response of $8 / 65 / 35$ PLZT. Acta Mater. 44(10), 4137 (1996). DOI: 10.1016/S1359-6454(96)00062-6.

[7] D. Damjanovic, Stress and frequency dependence of the direct piezoelectric effect in ferroelectric ceramics. J. Appl. Phys. 82(4), 1788 (1997). DOI: 10.1063/1.365981.

[8] S. B. Ren, C. J. Lu, H. M. Shen, and Y. N. Wang, In situ study of the evolution of domain structure in free-standing polycrystalline $\mathrm{PbTiO}_{3}$ thin films under external stress. Phys. Rev. B. 55(6), 3485 (1997). DOI: 10.1103/PhysRevB.55.3485.

[9] M. Algueró et al., Stress-induced depolarization of $\left(\mathrm{Pb}, \mathrm{La}^{2} \mathrm{TiO}_{3}\right.$ ferroelectric thin films by nanoindentation. Appl. Phys. Lett. 79(23), 3830 (2001)., DOI: 10.1063/1.1418258.

[10] J. K. Shang, and $\mathrm{X}$. Tan, Indentation-induced domain switching in $\mathrm{Pb}\left(\mathrm{Mg}_{1 / 3} \mathrm{Nb}_{2 /}\right.$ $\left.{ }_{3}\right)_{3} \mathrm{O}_{3}-\mathrm{PbTiO}_{3}$ crystal. Acta Mater. 49(15), 2993 (2001). DOI: 10.1016/S13596454(01)00199-9.

[11] F. R. Chien, F. J. Ubic, V. Prakash, and A. H. Heuer, Stress-induced martensitic transformation and ferroelastic deformation adjacent microhardness indents in tetragonal zirconia single crystals. Acta Mater. 46(6), 2151 (1998). DOI: 10.1016/S1359-6454(97)004448.

[12] A. B. Schäufele, and K. H. Härdtl, Ferroelastic properties of lead zirconate titanate ceramics. J. Am. Ceram. Soc. 79(10), 2637 (2005). DOI: 10.1111/j.1151-2916.1996.tb09027.x.

[13] B. Jiang, Y. Liu, and M. Li, In-situ observation of crack growth and domain switching around vickers indentation on $\mathrm{BaTiO}_{3}$ single crystal under sustained electric field. Acta Metall. Sin. 26(6), 772 (2013). DOI: 10.1007/s40195-013-0403-6.

[14] I. Bdikin et al., Nanoindentation induced piezoelectricity in $\mathrm{SrTiO}_{3}$ single crystals. Scripta Mater. 74, 76 (2014). DOI: 10.1016/j.scriptamat.2013.11.003.

[15] M. Deluca et al., Raman spectroscopy for the investigation of indentation-induced domain texturing in lead zirconate titanate piezoceramics. Scripta Mater. 63(3), 343 (2010). DOI: 10.1016/j.scriptamat.2010.04.040.

[16] D. Fang, Y. Jiang, S. Li, and C. T. Sun, Interactions between domain switching and crack propagation in poled $\mathrm{BaTiO}_{3}$ single crystal under mechanical loading. Acta Mater. 55(17), 5758 (2007). DOI: 10.1016/j.actamat.2007.06.024.

[17] G. A. Schneider, T. Scholz, J. Muñoz-Saldaña, and M. V. Swain, Domain rearrangement during nanoindentation in single-crystalline barium titanate measured by atomic force microscopy and piezoresponse force microscopy. Appl. Phys. Lett. 86(19), 192903 (2005). DOI: $10.1063 / 1.1920410$. 
[18] S. Mantri, J. Oddershede, D. Damjanovic, and J. E. Daniels, Ferroelectric domain continuity over grain boundaries. Acta Mater. 128, 400 (2017). DOI: 10.1016/ j.actamat.2017.01.065.

[19] D. M. Marincel et al., Domain wall motion across various grain boundaries in ferroelectric thin films. J. Am. Ceram. Soc. 98(6), 1848 (2015)., DOI: 10.1111/jace.13535.

[20] B. J. Rodriguez, Y. H. Chu, R. Ramesh, and S. V. Kalinin, Ferroelectric domain wall pinning at a bicrystal grain boundary in bismuth ferrite. Appl. Phys. Lett. 93(14), 142901 (2008). DOI: $10.1063 / 1.2993327$.

[21] J. X. Zhang et al., Large field-induced strains in a lead-free piezoelectric material. Nat. Nanotech. 6(2), 98 (2011). DOI: 10.1038/nnano.2010.265.

[22] T. Rojac et al., $\mathrm{BiFeO}_{3}$ ceramics: processing, electrical, and electromechanical properties. J. Am. Ceram. Soc. 97(7), 1993 (2014). DOI: 10.1111/jace.12982.

[23] S. Karimi et al., Crystal chemistry and domain structure of rare-earth doped $\mathrm{BiFeO}_{3}$ ceramics. J. Mater. Sci. 44(19), 5102 (2009). DOI: 10.1007/s10853-009-3545-1.

[24] S. Fujino et al., Combinatorial discovery of a lead-free morphotropic phase boundary in a thin-film piezoelectric perovskite, Appl. Phys. Lett. 92, 82 (2008).

[25] D. Kan et al., Universal behavior and electric-field-induced structural transition in rareearth-substituted $\mathrm{BiFeO}_{3}$. Adv. Funct. Mater. 20(7), 1108 (2010). DOI: 10.1002/ adfm.200902017.

[26] J. Walker et al., Dual strain mechanisms in a lead-free morphotropic phase boundary ferroelectric. Sci. Rep. 6, 19630 (2016).

[27] D. V. Karpinsky et al., Evolution of crystal structure and ferroic properties of La-doped $\mathrm{BiFeO}_{3}$ ceramics near the rhombohedral-orthorhombic phase boundary. J. Alloys Compd. 555, 101 (2013).

[28] I. O. Troyanchuk et al., Phase transitions, magnetic and piezoelectric properties of rareearth-substituted $\mathrm{BiFeO}_{3}$ ceramics. J. Am. Ceram. Soc. 94(12), 4502 (2011). DOI: 10.1111/ j.1551-2916.2011.04780.x.

[29] Y.-J. Wu et al., Pressure effect on structural and vibrational properties of Sm-substituted $\mathrm{BiFeO}_{3}$. J. Appl. Phys. 114(15), 154110 (2013). DOI: 10.1063/1.4826069.

[30] J. H. Wang, C. Q. Chen, and T. J. Lu, Indentation responses of piezoelectric films. J. Mech. Phys. Solids. 56(12), 3331 (2008). DOI: 10.1016/j.jmps.2008.09.009.

[31] D. O. Alikin et al., The effect of phase assemblages, grain boundaries and domain structure on the local switching behavior of rare-earth modified bismuth ferrite ceramics. Acta Mater. 125, 265 (2017). DOI: 10.1016/j.actamat.2016.11.063. 